\title{
Effect of needle number on drying rate of kiwi fruit in EHD drying process
}

\author{
Mohammad Jafar Dalvand", Seyed Saeid Mohtasebi, Shahin Rafiee
}

Department of Agricultural Machinery, Faculty of Agricultural Engineering and Technology, University of Tehran, Karaj, Iran; *Corresponding Author: Dalvand@ut.ac.ir

Received 20 October 2012; revised 21 November 2012; accepted 3 December 2012

\begin{abstract}
Electrohydrodynamic (EHD) drying is a novel method of non-thermal processing. In this drying method, drying can be carried out using either AC or DC high voltages. The thermodynamic considerations regarding the lowering of temperature under EHD drying include rapid rates of evaporation and exothermic interaction of the electric field with a dielectric material. Multi-point and plate electrode systems are efficient in accelerating drying of agricultural materials. The electrode produces corona wind, which resembles a round jet, impinges and removes moisture from the surface. The enhancement of drying rate by corona discharge from needle electrodes has been experimentally evaluated in this study. Effects of three different categories, one needle, nine needles and seventeen needles on drying rate of kiwi fruit were studied, moreover in each category, Experiments were carried out using DC voltage levels of 6 , 10.5 and $15 \mathrm{kV}$ and field intensities $4.5 \mathrm{kV} / \mathrm{cm}$. Results showed that the effect of needle number on drying rate was significant and drying rate of kiwi fruit reduced with increasing in needle numbers.
\end{abstract}

Keywords: Drying Rate; Electrode; Field Strength; High Voltage; Needle Number

\section{INTRODUCTION}

Drying is a common method of food preservation. Industrial drying involves the removal of water from a solid with the application of thermal, mechanical, or electrical energy. Conventional drying processes are based on convective, conductive, and radiative heat transfer using superheated steam, microwave, and freeze drying either alone or combined. High drying temperatures produce undesirable changes in the physical, chemical, and bio- logical properties of food [1]. Thermal drying degrades color, flavor, texture, and nutrients [2]. Ratti [3] found that freeze drying produces dehydrated products of superior quality but often has high energy costs. Energy losses in the product, dryer walls, vacuum pumps, and other dryer units should also be considered. Osmotic drying of food at lower energy rates and temperatures with favorable quality is desirable but results in a long drying time. Microwave drying also generates high heat during drying, and microwave-vacuum drying is more energy efficient than microwave-convective drying [4].

During drying, the liquid component usually undergoes a phase change. In thermal drying, an energy equivalent to the latent heat of vaporization must be supplied to create this change. Therefore, drying is a relatively energy intensive process. So reduction of energy usage in drying of biological materials is a major concern among environmentalists in terms of reducing greenhouse gas (GHG) emissions $[5,6]$. In response to the disadvantages of conventional drying processes, there is now a growing interest in the use of non-thermal processing of food and similar materials. An example of this is electrohydrodynamic (EHD) drying, which is a relatively new, non-thermal drying technique [7]. Since corona discharge can be produced at room temperature and atmospheric pressure, the technique is particularly attractive for low-temperature applications. Compared with hot air (convective) drying systems, EHD drying systems offer lower food production costs as well as superior quality in terms of physiochemical properties such as color, shrinkage, flavor, and nutrient content. Compared with convective and freeze drying, EHD drying systems have a simpler design, which consumes less energy [8].

Electrohydrodynamic (EHD) drying uses a secondary bulk flow which is known as corona wind or ionic wind. By applying high voltage to an electrode, ions are produced by the ionization of gas in a high electric field. As shown in Figure 1, these ions migrate to the electrode plate along electric field lines and collide with air molecules which then form the secondary bulk flow. As a result, the momentum transfer of gas is enhanced [9]. Chen 

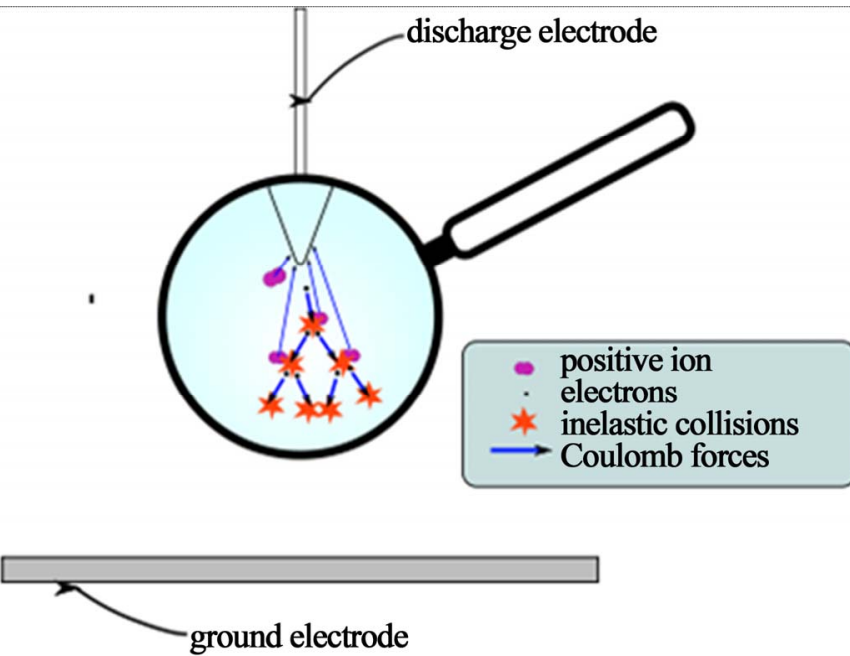

Figure 1. Mechanism of corona wind.

et al. [9] demonstrated that electric (ionic) wind was the main driving force for the accelerated drying rate. Lai and Lai [10] examined the influence of electric field parameters on the drying rate in a packed bed. A copper wire and a plate were located above and under the packed bed. It was found that drying rate depended on the strength of the electric field and the velocity of the cross flow. With absence of cross-flow, the enhancement in drying rate increased linearly with the applied voltage. In addition, the influence of corona wind was suppressed by the increase of cross-flow velocity.

Enhancement of heat and mass transfer in an inhomogeneous electric field has been studied extensively along with theoretical interests in electrohydrodynamic (EHD) and its potential application in cooling and drying [11,12]. Asakawa [13] performed a pioneering study on the promotion and retardation of heat transfer by electric field. Some researchers $[14,15]$ showed that, evaporation rates of water were increased about 4.0 - 8.5 times in a high electric field.

In the last decade, many researches, e.g. [16-19], have been much paid attention on the enhancement of heat and mass transfer in drying processes. However an investigation on effective parameters in drying process has not been reported by any researchers. The main objective pursued in this study is to investigate the effects of needle number on drying rate of kiwi fruit in a solar EHD dryer.

\section{MATERIALS AND METHODS}

\subsection{Materials}

Fresh kiwi fruits (c.v. Hayward) were considered in this study. Samples were transported to the physical laboratory of Faculty of Agricultural Engineering and Technology, University of Tehran, Karaj, Iran. Moisture con- tent of samples were determined on ASAE standard [20] and obtained as $84 \%$ w.b. After then required experiments were conducted in four days at laboratory temperatures ranging from $23^{\circ} \mathrm{C}$ to $27^{\circ} \mathrm{C}$.

\subsection{Experimental Setup}

The experimental setup, shown in Figure 1, consisted of an electric field apparatus supplied from a DC high voltage generator (Design and manufacture in power laboratory), with an output voltage of $0-30 \mathrm{kV}$ and maximum current of $2 \mathrm{~mA}$ with both polarities. In the present study, only positive polarity was utilized. The accuracy of the power supply is $\pm 100 \mathrm{~V}$ for voltage and $\pm 0.002 \mathrm{~mA}$ for current. In the point-to-plane configuration, a needle ( $0.1 \mathrm{~mm}$ in point diameter) was connected to the high voltage source, vertically above the center of plane $(25 \mathrm{~cm} \times 28 \mathrm{~cm})$ which was used as an electrically earthed reception plane. The distance between the cathode and the anode was adjustable between 0 to $8 \mathrm{~cm}$. Electric field was applied to the samples by adjusting the voltage and the electrode spacing.

The slice of samples with diameters of 3.5 - $5 \mathrm{~cm}$ were placed on the plane electrode (Figure 2). Weight loss of samples and their corresponding time, were measured with a digital balance with $0.01 \mathrm{~g}$ accuracy and a digital chronometer respectively. The ranges for temperature and humidity measurement instrument are $-40^{\circ} \mathrm{C}$ to $125^{\circ} \mathrm{C}$ and $0 \%$ to $100 \% \mathrm{RH}$ (non-condensing), respectively. The accuracy of the temperature measurement is 0.3 at $25^{\circ} \mathrm{C}$. The accuracy for the humidity measurement is $2 \%$ over $10 \%$ to $90 \% \mathrm{RH}$ at $25^{\circ} \mathrm{C}$.

\subsection{Methods}

The initial weight of the samples were measured and then samples were prepared for drying. Ambient condi- 


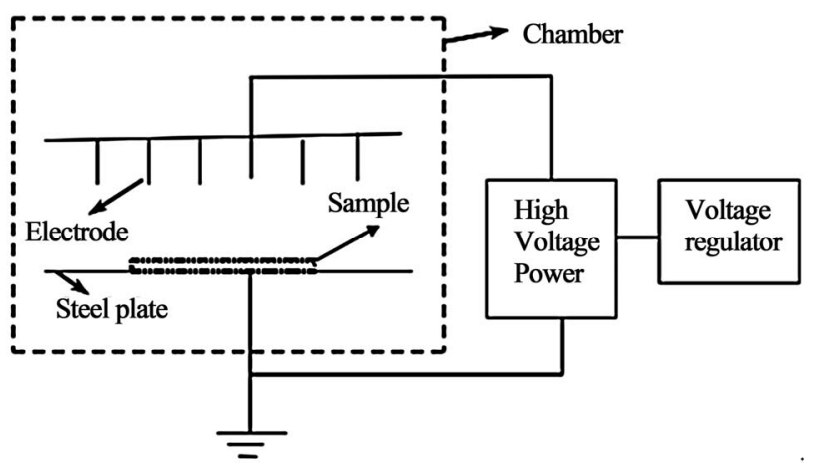

Figure 2. Diagram of EHD Drying.

tions in the laboratory during EHD drying were $24^{\circ} \mathrm{C}$ and $20.8 \%$ relative humidity. EHD drying experiments were performed at voltages of $6,10.5$, and $15 \mathrm{kV}$ and with field strength of $4.5 \mathrm{kV} / \mathrm{cm}$. samples were exposed continuously to drying during all experiments; weight was measured at 10 min intervals. Each set of measurements was completed in less than 30 seconds. During the entire experiment period, the change of ambient temperature was minimal since the lab was under well temperature control.

Moisture ratio (MR) of kiwi during drying experiments was calculated using the following equation [21]:

$$
M R=\left(M-M_{e}\right) /\left(M_{o}-M_{e}\right)
$$

where $M, M_{o}$, and $M_{e}$ are moisture content at any drying time, initial moisture content and equilibrium moisture content (kg water/kg dry matter), respectively. The values of $M_{e}$ are relatively small compared to those of $M$ or $M_{o}$, hence the error involved in the simplification is negligible [22]. The drying rate of kiwi was calculated using Equation (2) [23]:

$$
D R=\left(M_{t+d t}-M_{t}\right) / d t
$$

where $M_{t+d t}$ is moisture content at time $t+d t$ (kg water/ $\mathrm{kg}$ dry mater), $M_{t}$ is moisture content at time $t$ (kg water/ kg dry mater) and $d t$ is drying time (min).

In order to study the effect of needle number on drying rate of kiwi fruit, experiments carried out on three categories and three level of applied voltages, such as one needle, nine needles and seventeen needles, for applied voltages of 6, 10.5 and $15 \mathrm{kV}$. Each experiment lasted for $90 \mathrm{~min}$ and carried out in three replications. Moreover, Field strength of $4.5 \mathrm{kV} / \mathrm{cm}$ was being constant in all of experiments.

\section{RESULTS}

\subsection{Drying Rate Variation}

According to the experiments, there is no constant-rate drying period and in general, all drying operations occurred in the falling rate period, for this reason, the data which are reported in following Tables and Figures are average value upon entire period. As shown Table 1, the average values of drying rate in each category for kiwi fruit was obtained as $31.7 \times 10^{-3}(\mathrm{~kg}$ water $/ \mathrm{kg}$ dry mater time) varying from $27.6 \times 10^{-3}$ to $37.7 \times 10^{-3}$ for 1 needle category, $29.3 \times 10^{-3}$ (kg water $/ \mathrm{kg}$ dry mater time) varying from $25.0 \times 10^{-3}$ to $35.2 \times 10^{-3}$ for 9 needles category and $24.2 \times 10^{-3}$ (kg water $/ \mathrm{kg}$ dry mater time) varying from $19.9 \times 10^{-3}$ to $30.7 \times 10^{-3}$ for 17 needles category.

According to Table 1 maximum and minimum values of drying rate were $37.7 \times 10^{-3}(\mathrm{~kg}$ water $/ \mathrm{kg}$ dry mater time) and $19.9 \times 10^{-3}$ (kg water/kg dry mater time).

Figure 3 illustrates the changes of drying rate versus applied voltage and needles number of kiwi fruit for field strength of $4.5 \mathrm{kV} / \mathrm{cm}$.

The drying rate for kiwi fruit versus number of needles in constant field strength of $4.5 \mathrm{kV} / \mathrm{cm}$ is shown in Figure 4. The maximum values of drying rate obtained in applied voltage $15 \mathrm{kV}$ and one needle and in the other hand, in first category drying rate have highest value respect to entire period and is reduced by time.

\subsection{Moisture Ratio Variation}

The moisture ratio for kiwi fruit versus drying time in constant field strength of $4.5 \mathrm{kV} / \mathrm{cm}$ is shown in Figure 5. As seen in Figure 5, there were three categories (1, 9

Table 1. Values of drying rate with considering applied voltage and needle number.

\begin{tabular}{cccc}
\hline \multirow{2}{*}{$\begin{array}{c}\text { Applied } \\
\text { voltage }(\mathrm{kV})\end{array}$} & One needle & Nine needles & Seventeen needles \\
\cline { 2 - 4 } & 27.6 & 25.0 & 19.9 \\
10.5 & 29.9 & 27.8 & 22.0 \\
15 & 37.7 & 35.2 & 30.7 \\
\hline
\end{tabular}

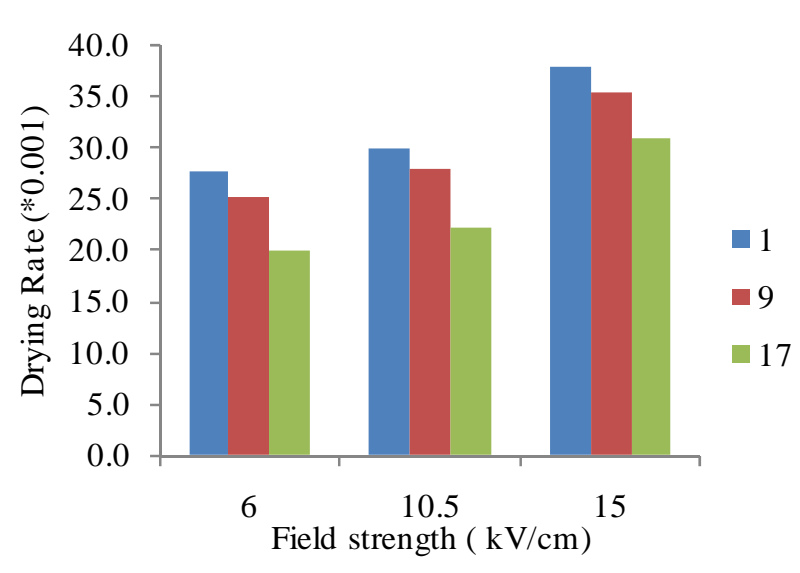

Figure 3. The effect of needle number and applied voltage on drying rate of kiwi fruit. 


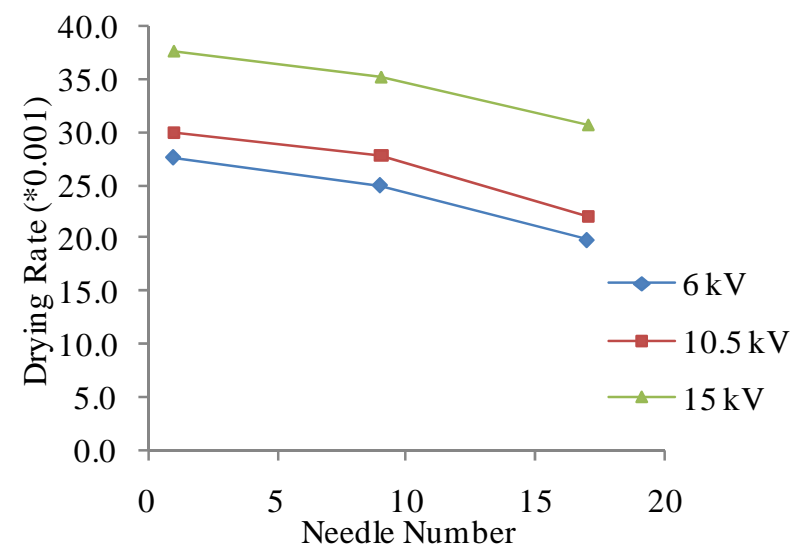

Figure 4. The variations of drying rate values versus needle number.

and 17 number of needles) in it, during drying time decreasing in moisture ratio (MR) occurred.

\section{DISCUSION}

\subsection{Drying Rate Variation}

Results indicated that, there was significant difference between drying rate of applied voltages $6,10.5$ and 15 $\mathrm{kV}$. Similar results were reported by Bai and Sun [24]. Moreover, the analysis of the data indicated that the effect of needle number on drying rate is significant at less than $1 \%$ probability level and this means that different needles number have different effects on drying rate that is shown in Table 1.

It is clear from Figure 3 that the drying rate decreases continuously as needle numbers increases. The experimental data of drying rate showed the difference between nine and seventeen needles was larger respect to different between one and nine needles, and this indicate further increase of the number of needles increases reducing the drying rate. It may be due to turbulence caused by the fields adjacent to each other. The changes in the drying process of an okara cake dried with an electrohydrodynamic (EHD) technique in an oven at $105^{\circ} \mathrm{C}$ were investigated by Li et al. [17]. They reported that the effect of the multiple point-to-plate system on the drying rate was not integral times higher than the single point to-plate system. The difference in results is probably due to differences in the electrode configuration, test temperature and type of product. Changing the needles position may be lead to a superposition of their fields.

Considerable point in Figure 4, is large difference between drying rate curve in applied voltage $15 \mathrm{kV}$ respect to 6 and $10.5 \mathrm{kV}$ and this indicate that with increasing applied voltage increases exponentially drying rate. In all of categories (1, 9 and 17 number of needles) increasing in drying rate of samples occurred due to de creasing in needle numbers.

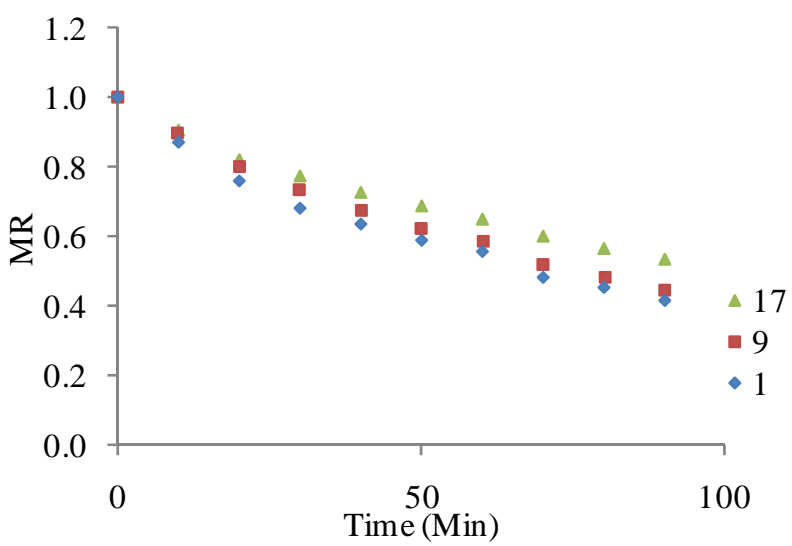

Figure 5. The variations of drying rate versus drying time for needle number of 1,9 and 17.

\subsection{Moisture Ratio Variation}

In first of drying period, drying rate have highest value respect to entire period and is reduced by time. Figure 5 indicates that the difference between the three categories is initially low, but over time this difference becomes more visible.

\subsection{Conclusions}

From the above discussion it can be concluded that:

- In field strength of $4.5 \mathrm{kV} / \mathrm{cm}$, maximum value for drying rate of kiwi fruit was obtained in applied voltage of $15 \mathrm{kV}$ and one needle number.

- In field strength of $4.5 \mathrm{kV} / \mathrm{cm}$, minimum value for drying rate of kiwi fruit was obtained in applied voltage of $6 \mathrm{kV}$ and seventeen needle numbers.

- In all of categories (1, 9 and 17 number of needles) increasing in drying rate of samples occurred due to decreasing in needle numbers.

- Further increase of the number of needles increases reducing the drying rate.

\section{ACKNOWLEDGEMENTS}

The authors would like to acknowledge the University of Tehran for supporting this project financially.

\section{REFERENCES}

[1] Bai, Y., Sun, B. and Yang, G. (2011) Drying characteristics of Spanish mackerel during electrohydrodynamic (EHD) drying. Power and Energy Engineering Conference (APPEEC), Wuhan, 25-28 March 2011.

[2] Wall, R., Howard, J.J. and Bindu, J. (2001) The seasonal abundance of blow flies infesting drying fish in southwest India. Journal of Applied Ecology, 38, 339-348. doi:10.1046/j.1365-2664.2001.00588.x

[3] Ratti, C. (2001) Hot air and freeze-drying of high-value foods: A review. Journal of Food Engineering, 49, 311- 


\section{9. doi:10.1016/S0260-8774(00)00228-4}

[4] Sunjka, P.S., Rennie, T.J., Beaudry, C. and Raghavan, G.S.V. (2004) Microwave-convective and microwavevacuum drying of cranberries: A comparative study. Drying Technology, 22, 1217-1231. doi:10.1081/DRT-120038588

[5] Raghavan, G.S.V., Rennie, T.J., Sunjka, P.S., Orsat, V., Phaphuangwittayakul, W. and Terdtoon, P. (2005) Overview of new techniques for drying biological materials with emphasis on energy aspects. Brazilian Journal of Chemical Engineering, 22, 195-201. doi:10.1590/S0104-66322005000200005

[6] Baker, C.G.J. (2005) Energy efficient dryer operation. Drying Technology, 23, 2071-2087. doi:10.1080/07373930500210556

[7] Bai, Y., Yang, G., Hu, Y. and Qu, M. (2012) Physical and Sensory Properties of electrohydrodynamic (EHD) dried scallop muscle. Journal of Aquatic Food Product Technology, 21, 238-247. doi:10.1080/10498850.2011.590271

[8] Lai, F.C. and Sharma, R.K. (2005) EHD-enhanced drying with multiple needle electrode. Journal of Electrostatics, 63, 223-237. doi:10.1016/j.elstat.2004.10.004

[9] Chen, Y., Barthakur, N.N. and Arnold, N.P. (1994) Electrohydrodynamic (EHD) drying of potato slabs. Journal of Food Engineering, 23, 107-119. doi:10.1016/0260-8774(94)90126-0

[10] Lai, F.C. and Lai, K.W. (2002) EHD-enhanceddrying with wire electrode. Drying Technology, 20, 1393-1405. doi:10.1081/DRT-120005858

[11] Darabi, J., Ohadi, M.M. and Devoe, D. (2001) An electrohydrodynamic polarization micropump for electronic cooling. Journal of Microelectromechanical Systems, 10, 98-106. doi:10.1109/84.911097

[12] Cao, W., Nishiyama, Y. and Koide, S. (2004) Electrohydrodynamic drying characteristics of wheat using high voltage electrostatic field. Journal of Food Engineering, 62, 209-213. doi:10.1016/S0260-8774(03)00232-2

[13] Asakawa, Y. (1976) Promotion and retardation of heat transfer byelectric field. Nature, 261, 220-221. doi:10.1038/261220a0

[14] Barthakur, N.N. and Arnold, N.P. (1995) Evaporation rate enhancement of water with air ions from a corona discharge. International Journal of Biometeorology, 39, 2933. doi:10.1007/BF01320890
[15] Hashinaga, F., Kharel, G.P. and Shintani, R. (1995) Effect of ordinary frequency high electric fields on evaporation and drying. Food Science and Technology International, 1, 77-81.

[16] Alemrajabi, A.A., Rezaee, F., Mirhosseini, M. and Esehaghbeygi, A. (2012) Comparative evaluation of the effects of electrohydrodynamic, oven, and ambient air on carrot cylindrical slices during drying process. Drying Technology, 30, 88-96. doi:10.1080/07373937.2011.608913

[17] Li, F.D., Li, L.T., Sun, J.F. and Tatsumi, E. (2006) Effect of electrohydrodynamic (EHD) technique on drying process and appearance of okara cake. Journal of Food Engineering, 77, 275-280. doi:10.1016/j.jfoodeng.2005.06.028

[18] Bajgai, T.R., Vijaya Raghavan, G.S., Hashinaga, F. and Ngadi, M.O. (2006) Electrohydrodynamic drying-A concise overview. Drying Technology, 24, 905-910. doi:10.1080/07373930600734091

[19] Goodenough, T.I.J., Goodenough, P.W. and Goodenough, S.M. (2007) The efficiency of corona wind drying and its application to the food industry. Journal of Food Engineering, 80, 1233-1238. doi:10.1016/j.jfoodeng.2006.09.016

[20] ASAE Standards (1998) S368.2. Compression test of food materials of convex shape. 44th Edition, American Society for Agricultural Engineering, St. Joseph.

[21] Togrul, T. and Pehlivan, D. (2003) Modeling of drying kinetics of single apricot. Journal of Food Engineering, 58, 23-32. doi:10.1016/S0260-8774(02)00329-1

[22] Aghbashlo, M., Kianmehr, M.H. and Samimi-Akhljahani, H. (2008) Influence of drying conditions on the effective moisture diffusivity, energy of activation and energy consumption during the thin-layer drying of barberries fruit (Berberidaceae). Energy Conversion and Management, 49, 2865-2871. doi:10.1016/j.enconman.2008.03.009

[23] Akpinar, E.K. and Bicer, Y. (2005) Modeling of the drying of eggplants in thin-layers. International Journal of Food Science and Technology, 40, 273-281. doi:10.1111/j.1365-2621.2004.00886.x

[24] Bai, Y.X. and Sun, B. (2011) Study of electrohydrodynamic (EHD) drying technique for shrimps. Journal of Food Processing and Preservation, 35, 891-897. doi:10.1111/j.1745-4549.2011.00542.x 